\title{
ACHIEVING SUSTAINABLE DEVELOPMENT THROUGH MAINTENANCE EXCELLENCE
}

\author{
Aditya Parida * \\ Luleå University of Technology, Luleå, Sweden \\ Diego Galar \\ Luleå University of Technology, Luleå, Sweden
}

Sustainability has been broadly defined as providing goods and services for current and future generations. Industries play a main role in that definition so more and more industries are working today to achieve sustainable development for their industry. Achieving a sustainable development needs strategic and continuous efforts involving the entire organization, where maintenance efforts play an important role. The management needs to understand and develop an appropriate strategic approach to understand the challenges involved and preparing all involved groups and personnel to achieve the sustainable development through application of maintenance performance measurement. Maintenance performance needs to be measured for managing and achieving the business objectives with a sustainable development goal. Maintenance plays a vital role in managing safety, energy saving, plant and machineries failure and productivity amongst others. To manage these activities, appropriate policy and planning is required to be developed enveloping the entire organization and necessary performance indicators are required to be identified to meet the unique requirements of the organization. In this paper, the authors have tried to discuss the issues and challenges associated with sustainable development with reference to maintenance performance measurement to achieve maintenance excellence.

Keywords: Sustainable engineering, maintenance, maintenance excellence, performance measurement

\section{INTRODUCTION}

Energy savings and sustainability will be the major challenges for maintenance teams in the near future. More than ever the focus needs to be on continual improvement and analysis to ensure optimum availability of the production lines. Developing asset sustainability is an integrated approach for creating long term stakeholders value through managing maintenance excellence. Managing asset sustainability effectively can support the organizations to enhance their competitive position and create additional value. Asset sustainability is critical issue for today's capital investment and productivity assessment. Industry is looking for new way is managing its asset in a global basis. It necessitates a systematic approach to create long-term stakeholders value by exploiting opportunities, while managing risks derived from economic, social and competitive business environment. Managing asset sustainability effectively can support the enterprises to enhance their competitive position and create additional share holders value. The development of an effective maintenance sustainable strategy can support the enterprises in managing asset sustainability in enhancing traditional valuation and shareholders value. According to Haarman et al, (2004), for all value drivers, maintenance can and does help to increase a company's economic value [03]. In a market where there is more demand than supply, greater machine availability results in more products, more income and thus higher value. On the other hand, lower maintenance costs produce higher value by avoiding expenditure.

Similarly, sustainability compromising factors as safety, health and environment (SHE) affects value. SHE accidents tend to necessitate substantial expenditure, which results in large negative cash flows. Damage caused to personnel, environment and image, for example, will increase expenditure. An even greater danger is loss of the license to operate because of an inability to comply with SHE legislation. No license to operate means no production and no income. 
In fact, there is currently less demand than supply and worldwide prices are under considerable pressure. The value potential here lies mainly in controlling costs and the smarter deployment of people and resources so sustainability factor here is becoming more and more important with the growing role of the regulating authorities. Once the value potential has been identified, the maintenance function must be organized accordingly. Which competencies are, and are not, important? VDM (Value Driven Maintenance), however, does so and it creates a link between value drivers and core competencies (see Figure 1). So the right-hand value circle must be configured from maintenance budgeting to cost analysis and the left-hand value circle must be organized from equipment performance planning to loss analysis. Interestingly, both value circles include the competencies of sustainability factors derived from SHE as reliability engineering, planning \& preparation and maintenance execution. These competencies are the link between the different maintenance value drivers.

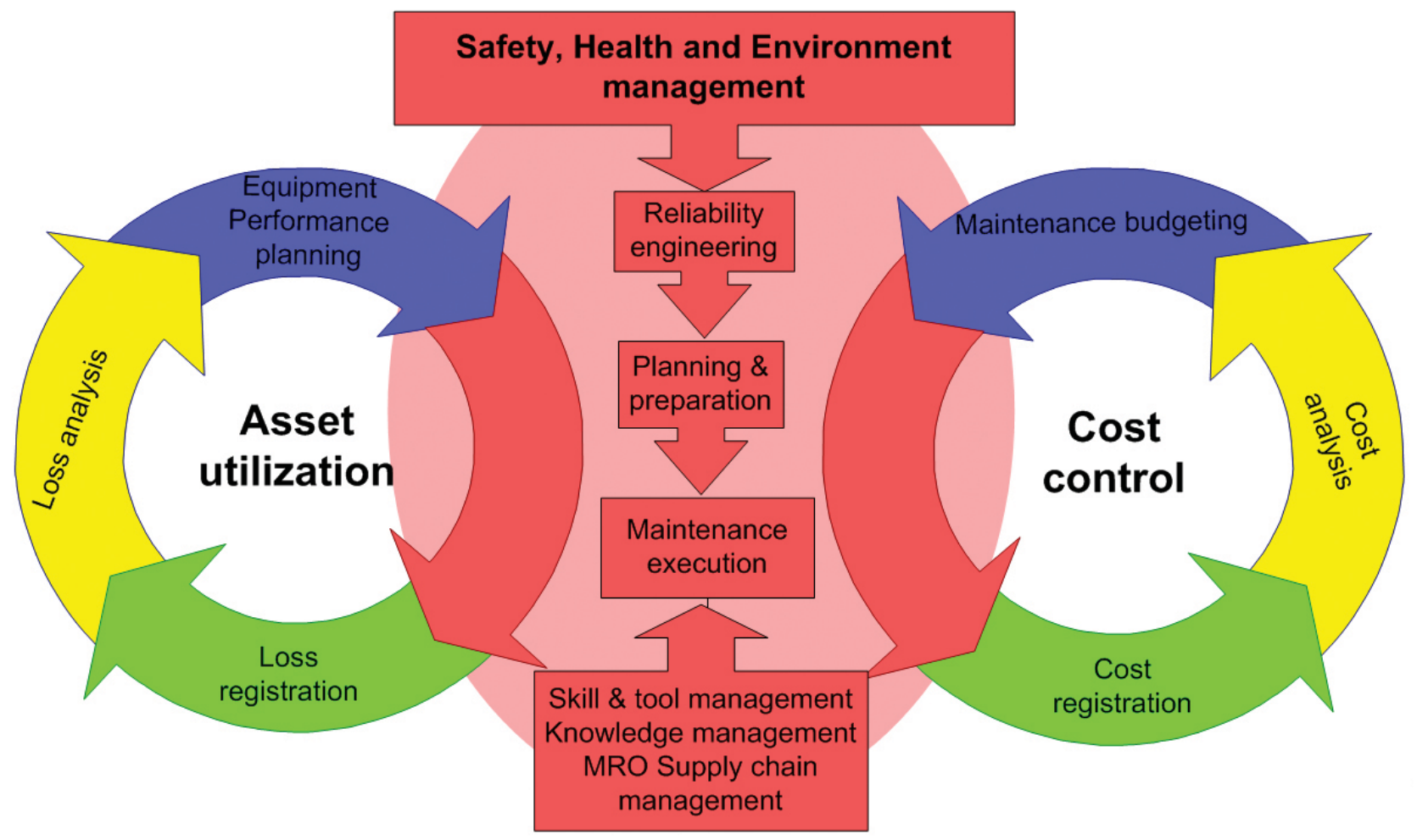

Figure 1: Asset management cost drivers in sustainability, (Haarman et al, 2004)

The growth in awareness of sustainable development practices in industry has imposed on industrial companies a need to integrate into their development strategy not only the current economical finality, but also some social and environmental requirements (Venkatasubramanian, 2005) [17]. These requirements are then, at least, passed on to their life cycle of product and production system. The technological development and changes in the last couple of decades under the dynamic global and competitive business scenario, besides the prevailing economic slow down are demanding a safe, reliable and sustainable asset management. The organizations need to reduce their environmental impact and achieve sustainability to achieve reduction of material, energy consumptions and waste production, while taking advantage of cost benefits etc (Bettley and Burnley, 2008) [01]. The sustainability definition is to meet the present needs without compromising the ability of the future generations to meet their own needs (World Commission, 1987) [09]. Thus, asset sustainability's integration for management decision with operation management is essential as many of the management decisions are long-term strategic ones rather than day-to-day planning and control (Bettley and Burnley, 2008) [01]. Kleindorfer et al., (2005), define sustainable operation management as "the set of skills and concepts that allows a company to structure and manage its business processes to obtain competitive return on its capital assets without sacrificing the legitimate needs of internal and 
external stakeholders and impact of its operation on people and the environment [07]. Sroufe et al., (2002), identified three sets of environmental management practices in sustainability as, dayto-day operational decisions involving shop floor personnel, medium term of resources deployment involving middle management and long term strategic issues involving top management decisions to create additional value [16]

Sustainable development for an organization essentially consists of its strategy and management policy for the operation and maintenance of its assets for its entire life cycle. The maintenance performance measurement and management thus plays an important role in the asset management and its sustainable development. To develop and control asset performance measurement or to launch maintenance improvement programme to achieve maintenance excellence, we need to streamline the information logistic: "right information in right formats and form to right person in right time". The application of information and communication technologies (ICT) facilitates the on-line and off-line condition monitoring and measurement of degradation of plant and machineries (Parida and Kumar, 2004) [13]. The maintenance process has also undergone several major developments and changes leading to proactive activities for the plant and machineries, besides the transformation from traditional 'fail and fix' or preventive maintenance to diagnostics and prognostics e-Maintenance methodology. With a need to achieve zero down time and zero defect for the asset, instantaneous response and decision-making, besides worldclass OEE performance; prognostics and diagnostics are used through embedded sensors and device to business tool (D2B). Plant Health Monitoring System (PHMS) thus, could consist of condition monitoring (CM) diagnostics and prognostics, and condition based operation and support, to improve the dependability and safety of the technical systems, besides decreasing life cycle cost of operation and support (Mobley, 1990; Campbell and Jardine, 2001; Soderholm and Akersten, 2002) [11, 02, 15]. This system delivers data and information, which indicates the health condition of the system. The stakeholders of the system are the receivers of the data and information (Lyytinnen and Hirschheim, 2002; ISO/IEC, 2002) [06].

In this paper, the authors have tried to discuss the issues and challenges for asset sustainability in section 2 after the introduction. In section 3 , how the sustainable development is achieved through maintenance excellence is discussed. Section 4 includes discussions and conclusions.

\section{Asset sustainability and its issues and challenges}

Asset sustainability forms part of sustainability management practices involving all the hierarchical levels of an organization from operational shop floor level to managerial at middle level to the long term strategic level to create additional value. The decision making is undertaken at all these levels to achieve reduction of material, energy consumptions and waste production, while taking advantage of cost benefits leading to asset sustainability development. These imply less environmental pollution on account of system longevity and optimum utilization of material and energy for limited resources scenario that governs the development of future systems. As it can be seen, asset sustainability depends on the performance characteristics of an asset or system. Thus, it is desirable that designers, manufacturer, operator and maintainers should be incorporated with the asset sustainability strategy for its development throughout the entire life cycle of the asset (Misra, 2008) [10]. Since, asset sustainability depends on asset performance characteristics; assessment of the asset performance plays a key role in the asset life cycle management. Performance of any asset cannot be managed if these cannot be assessed, monitored and controlled (Parida and Kumar, 2006) [13].

Sustainability means keeping an existing system operational and maintaining the ability to manufacture and field versions of the system that satisfy the original requirements. Technology sustainment analysis encompasses the ramifications of reliability on system management costs through availability and warranty etc. Sustainability also requires the management of technology obsolescence (forecasting, mitigation and strategic planning) (Misra, 2008) [10].

The business or corporate sustainability objectives are to increase the productivity, besides reduction of consumed resources without compromising product or service quality, competitiveness and profitability. The technology sustainability objectives are to; keep the systems operational, operations to meet the stakehold- 


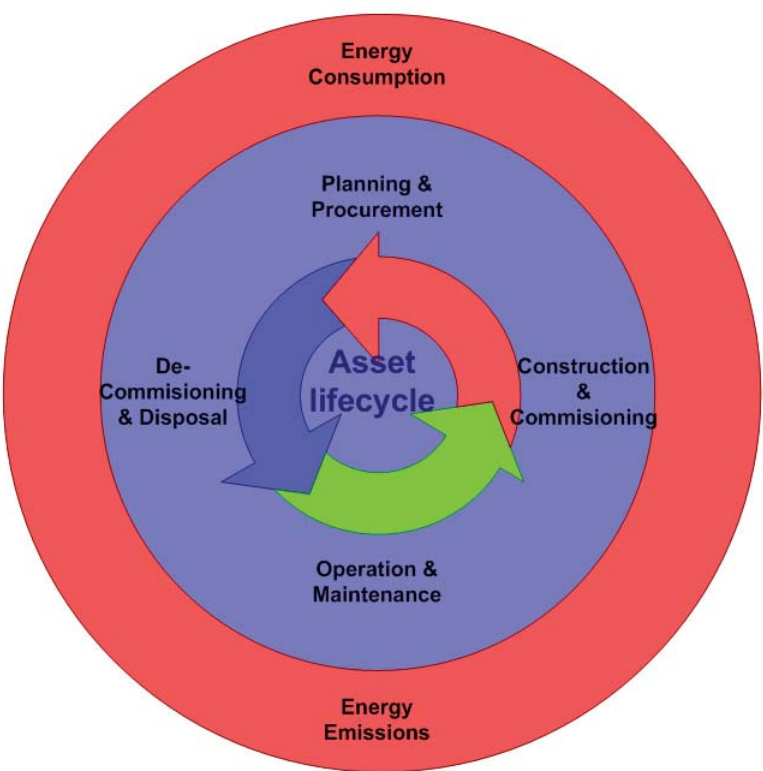

Figure 2: Asset management practices considering asset life cycle for sustainability (Infor, 2010)

ers' requirements and to revise the systems to meet the futuristic requirements.

For asset sustainability, under a challenging environment, organizations are trying to control and manage asset lifecycle with minimized energy consumption and energy emissions, See figure 2. Organizations use effective and efficient lean practices on four major areas of waste management; availability, performance, quality and energy consumptions, which are used as cost drivers. Thus, the global asset sustainability index consists of the above mentioned four major components and the first three factors are part of the asset's Overall Equipment Effectiveness (OEE). It is a challenge for the organizations to monitor and control these critical cost drivers through effective information technology management.

Thus, the e key issues involved with asset sustainability are:

- What are the needs for asset sustainability?, i.e. how to develop and translate the stakeholder's asset sustainability needs to operational level

- How to apply asset sustainability strategy?

- How to measure asset sustainability for improvement?

- How to implement of an appropriate internal and external communication system supporting asset sustainability?

- How to review, modify and maintain the asset sustainability?
- How to achieve free flow and transparency of information for asset sustainability?

- How to use the asset sustainability measures for measurement and decision making?

- How to integrate sustainability measures from shop floor to strategic level and viceversa?

The phenomenal advances in technology with smart material, nanotechnology, and biotechnology amongst others; provide adequate possibilities for developing sustainable assets, manufacturing processes and operations with minimum material and energy requirements. Since, sustainability is the need of many stakeholders, as you can see in figure 3 , with conflicting and contradictory requirements and interests, an integrated and holistic approach is needed to be adopted, developed and implemented. However this integration requires a high level of computation, extremely complex due to the multilocation structure of many companies with lots of information systems related to maintenance in each of them (CMMS, CM, phones, PDA, laptops, SCADA, ERP...). Replication of all data in order to perform this correlation is not feasible and would require enormous computation resources, that is why the concept tof cloud computing come up as a solution creating these metadata from all available information.

\section{Sustainable development through maintenance excellence}

Today's competitive manufacturing depends on lean manufacturing, besides providing the customer with lean service and life cycle costs for sustainable values. With the use of internet, web-enabled and wireless communication technology, achieving maintenance excellence through e-maintenance is transforming manufacturing companies to a service business supporting their customers anywhere and anytime. e-Maintenance can provide companies with predictive intelligence tools (such as watchdog agent) to monitor their assets (equipment, product, process, etc) through internet wireless communication systems to prevent them from unexpected breakdowns. In addition, these systems can compare product's performance through globally networked monitoring systems to allow companies to focus on degradation monitoring and prognostics rather than fault detection and diagnostics (Kocs and Lee, 2001) [08]. As per Muller et al., (2008), e-maintenance is the main- 
tenance support which includes the resources, services and management necessary to enable proactive decision process execution. The role of e-Maintenance is to monitor, collect, record and distribute real-time data about the asset

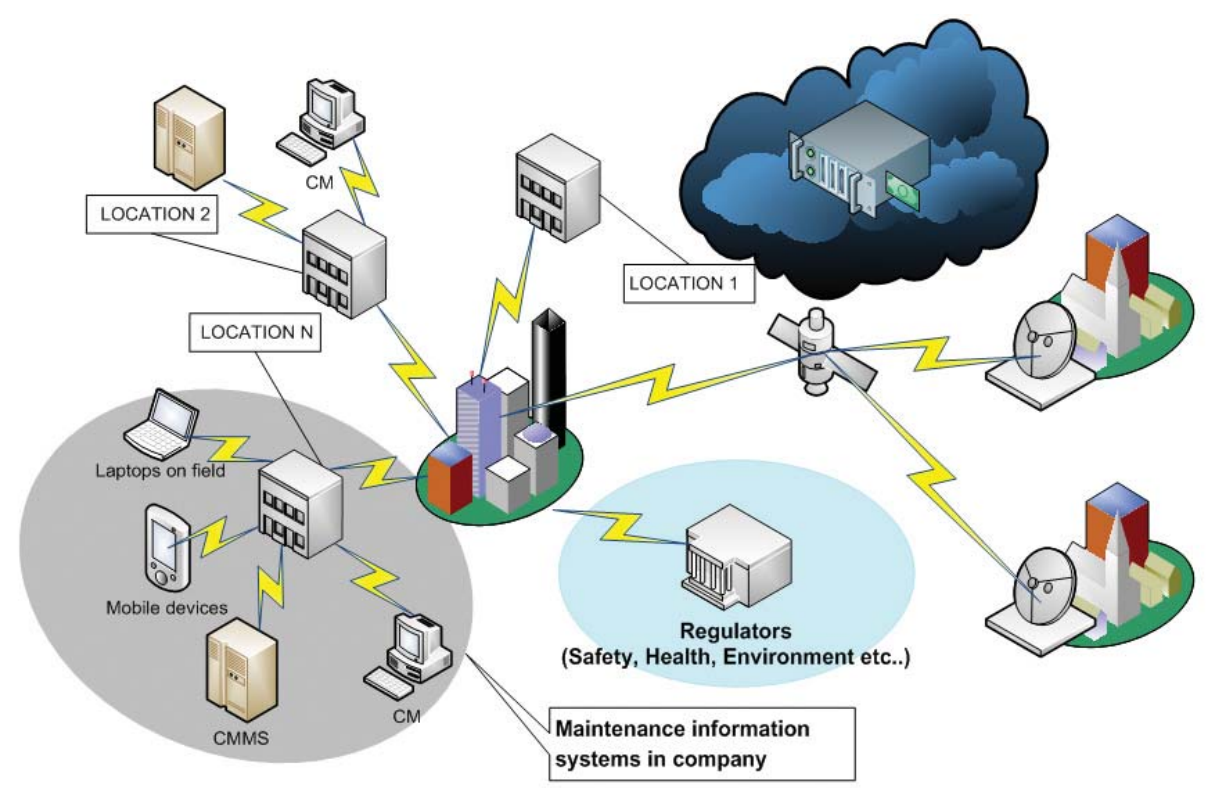

Figure 3: Need for cloud computing in CMMS and eMaintenance data integration

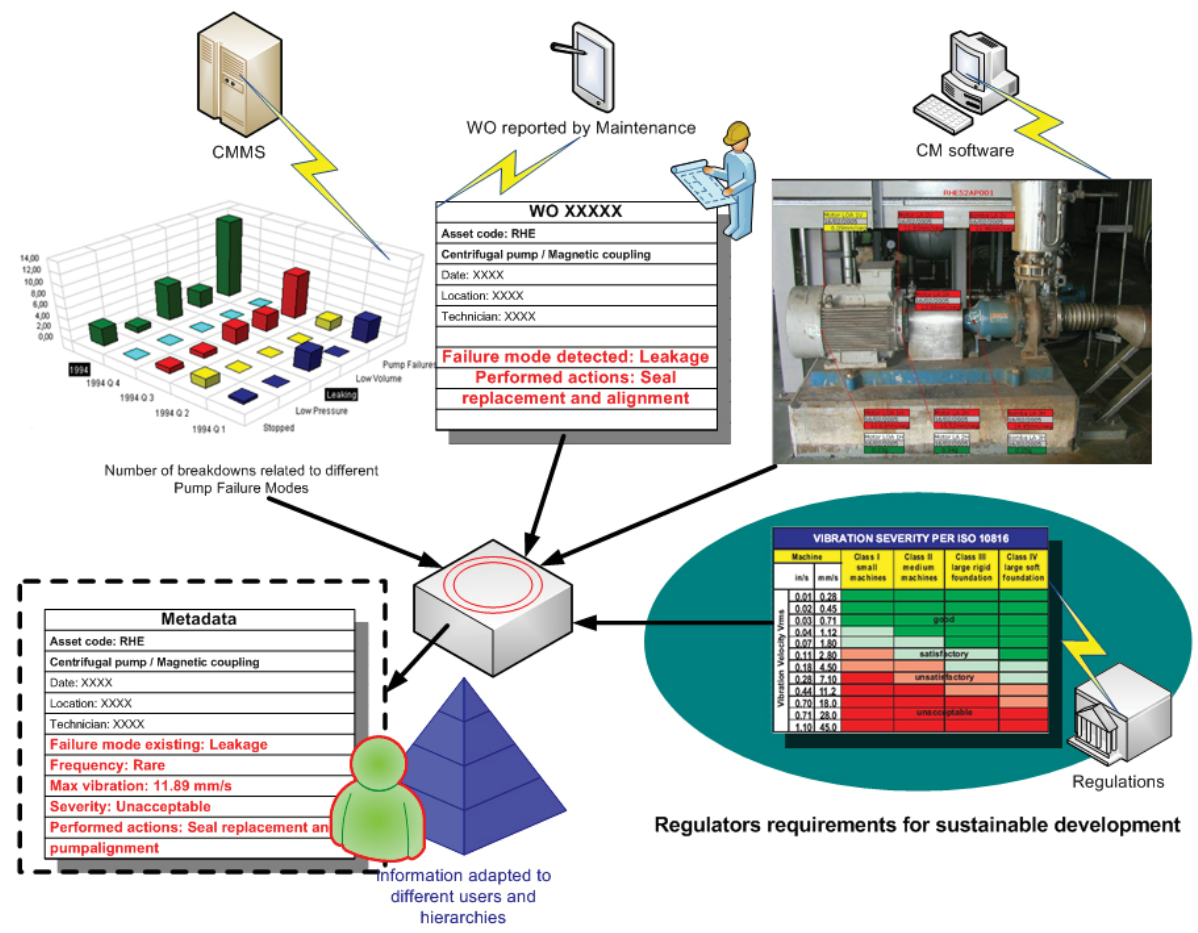

Figure 4: Decision-to-business platform, adopted (IMS, 2006)

health and sustainability, which facilitates the asset owners and managers in real-time decision making [12].

Device-to-Business (D2B) Platform transforms data and information from Computerized Maintenance Management System (CMMS) and e-Maintenance data sources (Condition Monitoring and other available information) to the e- business data source. Special emphasis should be done on regulators requirements, currently increasing and real contributors of sustainability development as you can see in Figure. 4. The platform delivers right information to the decision makers (right people and decision support software) for further activities. This information can be used as the input for other processes and systems, like; e-commerce and e-manufactur- 
ing. The D2B creates a knowledgebase which contains performance information for right decision making of the asset sustainability and management.

\section{CONCLUSION}

It is challenging for the enterprises to monitor and control the major cost drivers to achieve breakthrough lean best practices for asset life cycle to achieve sustainable development through maintenance excellence. Since, the enterprises are working under a dynamic and global competitive business scenario; an integrated sustainability strategy with flow of right information to right place and people in right format for decision making is possible through e-Maintenance and achieving maintenance excellence. There are various issues and challenges associated with asset sustainability, which needs to be considered while formulating the asset sustainability strategy. The commitments and involvements of the asset stakeholders form the foundation for this initiative.

\section{REFERENCES}

1) Bettley, A and Burnley, S (2008), Towards Sustainable Operation Management, Chapter 53 of Handbook of Performability Engineering, Edited by Misra, K. B, SpringersVerlag London Limited, pp. 875.

2) Campbell, J.D and Jardine, A. K. S (2001).Maintenance excellence: optimizing equipment life-cycle decisions. Marcel Dekker, New York, 2001.

3) Haarman Mark and Delahay Guy (2004) Value Driven Maintenance - New Faith in Maintenance, Mainnoviation, Dordrecht

4) Ifor (2010), Global asset sustainability, Infor EAM Whitepaper, downloaded from: http:// go.infor.com/greenEAM/ dated 18 March 2010.

5) IMS (2006), "Center for Intelligent Maintenance Systems". Available <http://www.imscenter.net/>

6) ISO/IEC 15288, (2002), Systems Engineering: System Life Cycle Processes, International Organization for Standardization, Geneva Commission Electrotechnique Internationale, Geneva.

7) Kleindorfer P. R; Singhal, K and Van Wassenhove L.N. (2005) Sustainable Operation Management. Production and Operation Management; 14 (4), pp. 482-492
8) Koc, M and Lee, J. (2001). A system framework for next-generation symposium on environmentally -conscious design and inverse manufacturing", Tokyo, Japan.

9) Lyytinnen, K and Hirschheim, R (1987), Information system failures: a survey and classification of the empirical literature, Oxford surveys in information technology. Oxford University Press, Oxford, 1987, p. 257-309.

10) Misra, K.B (2008), Performability Engineering: An Essential Concept in the 21st Century, Chapter 1 of Handbook of Performability Engineering, Edited by Misra, K. B, Springers-Verlag London Limited.

11) Mobley, R. K (1990), An introduction to predictive maintenance. Van Nostrand Reinhold, New York.

12) Muller, A.; Marquez, A. C and lung, B (2008). On the concept of eMaintenance: Review and current research, Reliability Engineering \& System Safety, 93, pp. 1165-1187

13) Parida, A. and Kumar, U. (2006). Maintenance Performance Measurement (MPM): Issues and Challenges. Journal of Quality in Maintenance Engineering, Volume 12, Number 3, pp. 239-251

14) Sandborn, $P$ and Meyers, J (2008), Designing Engineering Ssytems for Sustainability, Handbook of Performability Engineering, Edited by Misra, K. B, Springers-Verlag London Limited

15) Söderholm, P and Akersten, P. A (2002), Aerospace Diagnostics and Prognostics in a TQM Perspective. Proceedings of the 15th International Congress of COMADEM 2002, 2-4 September, Birmingham, UK, p. 80-89.

16) Sroufe R. P, et al. (2002), Environmental management practices -A framework. Greener Management International, 40, Winter, pp. 23-44 2.

17) Venkatasubramanian, $V$ (2005), Prognostics and diagnostic monitoring of complex systems for product lifecycle management: challenges and opportunities, Comput Chem Engineering, Volume 29, Issue 6, pp: 1253-63

18) World Commission (1987), On Environment and Development, Our common future, 1987

Paper sent to revision: 29.05.2012.

Paper ready for publication: 22.06.2012. 